\title{
FAMILY PLANNING AND ITS IMPLICATIONS
}

\section{Glory. A. Msacky, MD3, Muhimbili University of Health and Allied Sciences}

DMSJ 2012; 19: 8-12 http://dx.doi.org/10.4314/dmsj.v19i1.2

\begin{abstract}
Background: Sub-Saharan Africa has the highest average fertility rate in the world. In 2009, the average number of births per woman was 5.1-more than twice as many as in South Asia (2.8) or Latin America and the Caribbean (2.2). More than 100 million women in less developed countries, or about 17 percent of all married women, would prefer to avoid a pregnancy but are not using any form of family planning. Currently, approximately 24.8 percent of African women have unmet needs for family planning; this simply means 24.8 million women of reproductive age who prefer to avoid or postpone childbearing are not using any method of contraception.
\end{abstract}

Objective: To make a review of trends of family planning practice in Sub Saharan Africa from 1980 to 2010 among women of reproductive age.

Methodology: Meta-analysis of detailed literature by authors of articles published since 1980 from various sources, including Demographic Health Survey (DHS) of 1990 to 1995, 2000 to 2005, and of 2005-2010 from Sub-Saharan Africa such as South Africa Demographic Health Survey (SADHS) and Tanzania (TDHS); and observation on the relationship between family planning use and fertility in Africa.

Findings: An analysis of fertility trends in 23 countries of Sub-Saharan Africa from 1980 to 1995 showed that in two-thirds of the countries there was evidence of fertility decline, with a particularly rapid decline in Kenya and Zimbabwe. Furthermore 2010 statistics show the African total fertility rate to be standing at 4.7. These rates reflect contraceptive prevalence of these specific regions.Generally in all world regions, contraceptive use corresponds with fertility patterns. In regions where contraceptive use is widespread, fertility is low but in regions where contraceptive use is uncommon, fertility is high.

Conclusion: The paper has shown that the high fertility pattern in Africa is among others, a result of the ineffectiveness of family planning programs.

Recommendation: The overall low rate of contraceptive prevalence and high unmet need for family planning suggests the need for African national governments and population policy makers to rethink access to contraceptives.

Correspondence to: Glory. A. Msacky E-MAIL: glorymsacky@gmail.com

\section{BACKGROUND}

Sub-Saharan Africa has the highest average fertility rate in the world. In 2009, the average number of births per woman was 5.1-more than twice as many as in South Asia (2.8) or Latin America and the Caribbean (2.2) [1]. Both African women and men value fertility in the African community very 
highly. It is thus not surprising that, even for unmarried women and teenage girls, pregnancy has a positive value not generally experienced in white communities [2].

The programme of action of the 1994 International Conference on Population and Development, a landmark conference states, "Governmental goals for family planning should be defined in terms of unmet needs for information and services."[3].

Unmet need measures the gap between demand for family planning and use of contraception. Expressed as the percentage of sexually active women who do not want additional children but are not using any family planning method, low levels of this measure are often considered a precursor of fertility decrease. More than 100 million women in less developed countries, or about 17 percent of all married women, would prefer to avoid a pregnancy but are not using any form of family planning.[4] Demographers and health specialists refer to these women as having an "unmet need" for family planning - a concept that has influenced the development of family planning programs for more than 20 years. Over the past decade, rising rates of contraceptive use have reduced unmet need for family planning in most countries.

In some countries, however, unmet need remains persistently high (more than one-fifth of married women) or is increasing, indicating that greater efforts are needed to understand and address the causes of unmet need. Empirical findings have shown that couples are having more children than they want due to unavailability of family planning services to enable them prevent unwanted pregnancies. In this regard Africa is a good point of reference.[5] Currently, approximately 24.8 percent of African women have an unmet need for family planning; this simply means 24.8 million women of reproductive age who prefer to avoid or postpone childbearing are not using any method of contraception[6]. Net increases in unmet need were noted in a few countries, particularly Chad and Uganda, indicating rising demand for family planning that is not being met in these countries.

The study done in South Africa by South Africa Demographic Health Survey (SADHS) found almost universal knowledge of at least one contraceptive method. Three-quarters of all women interviewed indicated that they had used a contraceptive method at some stage during their lives, while 61 per cent of sexually active women reported that they were currently using contraception[7].

\section{OBJECTIVE}

Broad Objective: To make a review of trends of family planning practice in Sub Saharan Africa from 1980 to 2010 among women of reproductive age.

Specific Ojectives: To review the current trends of family planning practice in SSA and to expore the relationship between family planning use and fertility in SSA

\section{METHODOLOGY}

Literature search: I searched through Medline (using PubMed) and EMBASE for published articles on the effect of family planning on reduction of fertility, and on the trends of family planning in SSA. I divided the search to capture the themes of (1) family planning (2) reproductive women (3) current trends (4) Africa (SSA). I developed search terms for these themes, combined the terms with each theme, and then combined the different theme searches. 
Data extraction: I extracted the data based on citation, publication date, study name, location, and dates carried out, with subjects on demographic characteristics, inclusion/exclusion criteria, and number enrolled.

Inclusion and exclusion criteria: I screened the titles and abstracts from the individual database search results from 1980-2010, pooled the potentially eligible studies, retrieved full-text articles, and then assessed whether they met the inclusion criteria. I excluded publications that did not report primary data (commentaries, perspectives, secondary and meta-analyses).

\section{FINDINGS}

\section{Trends of Family Planning Practice in Africa}

Contraceptive prevalence is lower in Sub-Saharan Africa than in other parts of the world. An analysis of fertility trends in 23 countries of Sub-Saharan Africa from 1980 to 1995 showed that in two-thirds of the countries there was evidence of fertility decline, with a particularly rapid decline in Kenya and Zimbabwe[8]. In 1990 the contraceptive prevalence rates estimated in all African countries were less than 15 percent except in Zimbabwe, Botswana and Kenya [9,10]. In 2009 it was estimated that 35 million women in Africa had an unmet need for family planning.[11]. Net increases in unmet need were noted in a few countries, particularly Chad and Uganda, indicating rising demand for family planning that is not being met in these countries.

Trends in modern CPR and unmet need indicate that in countries such as Zambia, Madagascar, Malawi, and Kenya, decline in unmet need has corresponded with an increase in family planning. In other countries, such as Senegal, Mali, Ghana, and Eritrea the gap has remained wide and consistent. Today, 24.8 percent of women want to use family planning but lack access leaving them with no other option but to continue having unwanted pregnancies.[12]. When examining the concept of contraceptive prevalence, they provide an estimate of the gap between demand and utilization of family planning.

The analyses of fertility based on Demographic Health Survey (DHS) data show that although fertility levels in Africa are still the highest in the world, in several African countries a declining trend can be observed. Tanzania is among them. The fertility level has played a significant role in causing a high population growth rate, estimated to be around 3 percent per year. As a consequence, the government established a Tanzania National Population Policy (TNPP), which, among other things, encourages a reduction in fertility.

The figure below presents the percentage of currently married women (15 to 49 years) using a contraceptive method between 1986 and 1995. Of the countries in Eastern and Southern Africa, South Africa has the highest contraceptive prevalence rate (50 percent) followed by Zimbabwe (48 percent). Tanzania has the lowest of all countries.

Percentage of currently married women (15-49 years) using a contraceptive method in Eastern and Southern African 


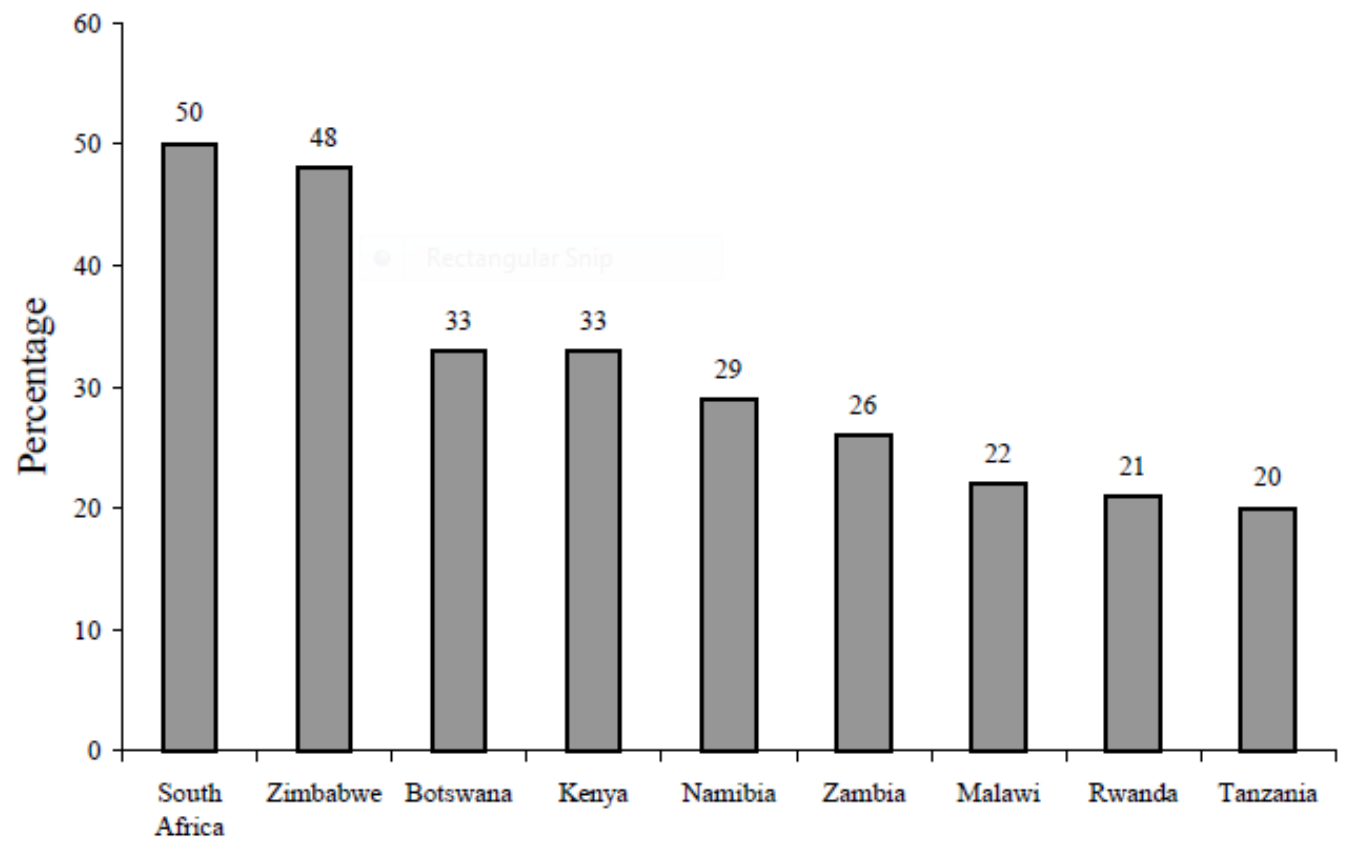

\section{The Relationship Between Family Planning Use and Fertility in Africa}

In Africa, the pattern of fertility is linked to a number of factors. Among others, the state of fertility in Africa is purely a result of the low prevalence rate of contraceptive use. The 2009 population data sheet indicates that in Africa an average of 36 babies are born per 1000 of the population while in other regions only 11 babies are born. Furthermore 2010 statistics show the African total fertility rate to be standing at 4.7. These rates reflect contraceptive prevalence of these specific regions.

The existence of strong family planning programs is a prerequisite to reducing fertility. Generally in all world regions, contraceptive use corresponds with fertility patterns[13, 14]. In regions where contraceptive use is widespread, fertility is low but in regions where contraceptive use is uncommon, fertility is high[15,16]. This is also supported by data shown in Table. 1. It can be seen that the increase in contraceptive prevalence means a decrease in fertility and consequently results in slowed natural increase. By expanding the use of family planning in Sub-Saharan Africa, countries can limit the expected growth in population to below 1.8 billion by 2050 .

Table 2 


\begin{tabular}{|c|c|c|c|c|c|c|}
\hline Region/Country & $\begin{array}{l}\text { Population } \\
\text { Mid- } \\
\text { 2009(millions) }\end{array}$ & $\begin{array}{l}\text { Births per } \\
1.000 \\
\text { population }\end{array}$ & $\begin{array}{l}\text { Deaths per } \\
1.000 \\
\text { population }\end{array}$ & $\begin{array}{l}\text { Rate of } \\
\text { Natural } \\
\text { Increase } \\
(\%) \\
\end{array}$ & $\begin{array}{l}\text { Total } \\
\text { Fertility } \\
\text { Rate }\end{array}$ & $\begin{array}{l}\% \text { of married } \\
\text { women } 15-49 \\
\text { using } \\
\text { Contraception }\end{array}$ \\
\hline World & 6.892 & 20 & 8 & 1.2 & 2.5 & 62 \\
\hline More Developed & 1.237 & 11 & 10 & 0.2 & 1.7 & 71 \\
\hline Less developed & 5.656 & 22 & 8 & 1.4 & 2.7 & 60 \\
\hline $\begin{array}{l}\text { Less developed } \\
\text { (Excl. China) }\end{array}$ & 4.318 & 25 & 8 & 1.7 & 3.1 & 52 \\
\hline Least Developed & 857 & 35 & 12 & 2.3 & 4.5 & 29 \\
\hline Africa & 1030 & 37 & 13 & 2.4 & 4.7 & 29 \\
\hline America & 929 & 17 & 7 & 1.0 & 2.2 & 75 \\
\hline Asia & 4.157 & 19 & 7 & 1.2 & 2.2 & 66 \\
\hline Europe & 739 & 11 & 11 & 0.0 & 1.6 & 70 \\
\hline Oceania & 37 & 18 & 7 & 1.1 & 2.5 & 82 \\
\hline Niger & 15.9 & 52 & 17 & 3.5 & 7.4 & 11 \\
\hline Libya & 6.5 & 23 & 4 & 1.9 & 2.7 & 42 \\
\hline Kenya & 40.0 & 37 & 10 & 2.7 & 4.6 & 46 \\
\hline DRC & 67.8 & 47 & 17 & 2.9 & 6.4 & 21 \\
\hline
\end{tabular}

Source: Population Reference Bureau. World Population Data Sheet. 2010.

\section{CONCLUSION}

Generally, the success of family planning programs in Africa is affected by poverty, inadequate knowledge about contraception, limited ability to make independent decisions about using family planning or about when to have children, strong compliance with cultural and religious norms and lack of experience in obtaining family planning services.[18] Some specific service delivery strategies that have been found to be effective in Africa are those that promote spacing methods, give women the means to assume responsibility over contraceptive adoption, and allow women to use contraception without their partners' knowledge [19].

Programs are likely to be most successful when they reach beyond the conventional boundaries of service provision to influence and alter the cultural and familial factors that limit voluntary contraceptive use.

\section{RECOMMENDATION}

The overall low rate of contraceptive prevalence and high unmet need for family planning suggests the need for African national governments and population policy makers to rethink access to contraceptives. For fertility to fall to low levels, many factors are key. These include a significant increase in the use of family planning; family planning programs that have delivery points throughout the country; a wide range of contraceptive methods; easy availability of contraceptives; adoption of a reproductive health approach that can reach adolescents, men, and unmarried people 
who are most likely to accelerate progress toward fertility decline in Africa [20]. These cannot resolve all our problems, but it will help achieve a lot of he key development goals, including all Millenium Development Goals

(MDGs).

A stable population can be maintained in Africa given that populations have a wide range of family planning services to help them attain the exact number of children they want. Until full access to reproductive health becomes part of national government priorities, Africa and the world will continue to suffer disproportionately from population growth. Therefore total government commitment should be put in the promotion of reproductive rights through making family planning services accessible for all in need and offering more choices including sterilization.

As far as the current situation is concerned, the significance of contraceptives in today's world does not only lie in its power to reduce fertility rates but it also addresses other population problems, and government must provide sufficient support to family planning programs so as to fully realize other health related goals. These include reducing the number of maternal deaths and other health complications resulting from unsafe abortions by women of reproductive age.

\section{REFERENCES}

1.World Bank. 2009. World Development Indicators. Washington, DC: World Bank

2.Preston-White, E., M. Zondi, G. Mavundla and H. Gumede (1990). Teenage pregnancy, whose problem?Realities and prospects for action in Kwazulu-Natal. South African Medical Journal,

3. United Nations (UN), "Programme of Action of the International Conference on Population and Development," accessed online at www.unfpa.org/icpd/reports\&doc/icpdpoae.html, on Dec. 9, 2002

4. United States Agency for International Development. 2009. The status of Family Planning in subSaharan Africa Briefing Paper.

5. International Development. 2009. The status of Family Planning in sub-Saharan Africa Briefing Paper.

6. Department of Economic and Social Affairs, Population Division. 2011. "Global population to pass 10 billion by 2100, UN projections indicate" United Nations. http://www.un.org/apps/news/story.asp?NewsID=38253 Accessed 26 May 2011.

7. South African Demographic Health Survey (SADHS) Project Team (1999). South Africa in transition: selected findings from the South African Demographic Health Survey, 1998. Pretoria: Government Printers.

8. Saxena P.C; Jurdi R. Impact of Proxitate Determinants on the recent fertility in Yemen

9.Aloo-Obunga, C. 2003. Country Analysis of Family Planning and HIV/AIDS: Kenya. Policy Project, Washington DC. 
10. Lucas, D. 1992. - Fertility and Family Planning in Southern and Central Africa.ll Studies in Family Planning 23 (3): 145-58.

11. World Health Organisation. 2011. World Health Statistics John A. Ross and William L. Winfrey, "Unmet Need for Contraception in the Developing World and the Former Soviet Union: An Updated Estimate," International Family Planning Perspectives 28, no. 3 (2002).

12.Dodoo, F. N 2001 Fertility preferences and contraceptive use: A profitable nexus for understanding the prospects for fertility decline in Africa" workshop on prospects for fertility decline in high fertility countries. population division. Department of economic and social affairs. United Nations secretariat. 9-11 July 2001.

13.Bertrand, J.T., E.K. Bauni, R.J. Lesthaeghe, M.R. Montgomery, O. Tambashe, and M.J. Wawer (1993): Factors Affecting Contraceptive Use in Sub-Saharan Africa. Washington D.C.: National Academy Press.

14.Dodoo, F. N 2001 Fertility preferences and contraceptive use: A profitable nexus for understanding theprospects for fertility decline in Africa" workshop on prospects for fertility decline in high fertility countries.population division. Department of economic and social affairs. United Nations secretariat. 9-11 July 2001

15.Williamson L.M, ParkesA. Wight D. Petticre M; Hart G. Limits to modern contraceptive use among young women in developing countries: a systematic review of qualitative research. 2009. Reproductive Health. Vol 6. No 3. Page 9

16. Saxena P.C; Jurdi R. Impact of Proxitate Determinants on the recent fertility in Yemen

17. Gribble J and Joan Haffey, Reproductive health in sub-Saharan Africa. Population Reference Bureau. 2008

18.Caldwell, J. C., and P. Caldwell. 1987. - The Cultural Context of High Fertility in Sub-Saharan Africa.l Population and Development Review 13 (3): 409-37.

19. Caldwell, J. C., and P. Caldwell. 2002. -Africa: The New Family Planning Frontier.\| Studies in Family Planning 33 (1): 76-86

20. Population Reports. 2003. The Reproductive Revolution Continues. Series M. Number 17 Page 8; Gribble J and Haffey,J . 2008. Reproductive health in sub-Saharan Africa. Population Reference Bureau. 